regions may partly reflect the increased complexity of transfer arrangements. There are at least 19 units in the four regions which are prepared to accept neonatal transfers, and they are often open to transfers from units outside their own region. The Emergency Bed Service keeps a daily record of cots available at all "receiving" units, but not all requests are made through the service. This may be because a cot is sought in a unit outside Greater London and so is not covered by the service or because the member of staff requesting the transfer did not know about or want to use the service.

In 1985 the Maternity Services Advisory Committee asked a series of questions on an "action checklist" for care of small and ill babies.' The following questions are relevant to the findings of this survey:

- Does each maternity unit have ready access to a designated regional perinatal centre to which mothers who are expected to have babies who will require intensive care can be referred for care and delivery?

- Do the staff of each maternity unit understand the arrangements for the emergency admission or transfer of babies to an appropriate neonatal unit?

- Are arrangements for the acceptance and transfer of babies to regional perinatal centres satisfactory?

- Are arrangements monitored regularly to maintain them at a high point of efficiency?

Many regions have perinatal working parties or committees that ask these questions and occasionally report on the position..$^{5.8}$ There are inadequate national data to monitor or compare the position in different regions, except through surveys such as this. If regional neonatal services were reviewed regularly according to an agreed format, as has been recommended, ${ }^{19}$ the findings might confirm whether the differences that we have observed between regions indeed indicate unequal provision of resources or unequal access to neonatal care.
This report was written by Miranda Mugford, with helpful comments from those taking part in the survey and from colleagues at the National Perinatal Epidemiology Unit and elsewhere.

The regional coordinators for the survey were: D Milligan (Northern), P Dear (Yorkshire), R Pearse ('Trent), C Roberton (East Anglia), A Whitelaw and J Chapple (North West Thames), A Ramsden (North East Thames), A Greenough (South East Thames), N McIntosh (South West Thames), M Hall (Wessex), A Wilkinson (Oxford), P Fleming (South Western), I Morgan (West Midlands), M Weindling (Mersey), D Sims (North Western), J Murphy and P Rowlandson (Wales), T Turner(Scotland), H Halliday (Northern Ireland). Supraregional coordinators and members of the BAPM working party were: $\mathrm{N}$ McIntosh, $M$ Levene, $T$ Turner, and H Halliday. National data collection and analysis were carried out by S Langdale and M Mugford at the National Perinatal Epidemiology Unit. Miranda Mugford is funded by the Department of Health and Social Security, Sarah Langdale's salary was paid by Baby Life Support Systems; additional costs were met by the British Association of Perinatal Medicine with a contribution from Simonsen and Weel Ltd.

The survey could not have taken place without the help of staff in all the units where births take place throughout the UK, and we thank them for their help.

1 Maternity Services Advisory Committee. Maternity care in action. 111. Care of th mother und baby. London: Department of Health and Social Security, 1985. Sims DG, Wynn J, Chiswick ML. Outcome for newborn babies declined admission to a regional intensive care unit. Arch Dis Child 1982:57:334-7.

3 Macfarlane A, Mugford M. Birth counts: statistics of pregnancy and childhirth. Vol II. London: HMSO, 198

+ Chamberlain G. Gunn P. Birthplace: report of the confidential enquirv into facilities avialable at the place of birth. Chichester: Wiley, 1987.

5 Welsh Office. Wales perinatal mortality initiative 1984-1986. Cardiff: Welsh Office, 1986.
(a)

6 Northern Regional Health Authority. Collaborative survey of perinatal and late neonatal mortality. Report 1985 . Newcastle: Northern RHA, 1986.

7 Yorkshire Regional Health duthority. Special and intensize care of new horns in Yorkshire Regional Health Authority. Special and intensac
the Yorkshire region. Harrogate: Yorkshire RHA, 1985.

8 Nursing Department, Oxford Regional Health Authority. Special care baby units study. Second report 1986. Oxford: Oxford RHA, 1987.

9 Mugford M, Mutch L, Elbourne D. Standard perinatal data: suggestions for regular review of facilities for perinatal care within a regional health authority. Community. Med 1985;7:157-68

Accepted 14 November 1988
Subdepartment of General Practice, Medical School, Sheffield S10 2RX

Nigel Mathers, MD, research fellow

Paul Hodgkin, MRCGP, lecturer

Correspondence to: Dr Mathers.

\title{
The Gatekeeper and the Wizard: a fairy tale
}

\author{
Nigel Mathers, Paul Hodgkin
}

The recent discussion document Review of Restrictive Trade Practices Policy threatens to make illegal the near monopoly of general practitioners to refer patients to hospital consultants.

Once upon a time in a green and pleasant land there lived a Gatekeeper and a Wizard. The Wizard lived in a great white castle above a town. In this castle he had a marvellous crystal ball that could tell him why people were poorly. He would then use one of his powerful magic potions to make them better again. The Wizard was a very clever man.

The Gatekeeper lived in a big house next to the entrance of the castle. His job was to decide who was poorly enough to need to see the Wizard and open the gate into the castle for them. The Gatekeeper was also very clever, and he too had magic potions to make poorly people better. After all, the Wizard and the Gatekeeper had both gone to the same school for wizards, although they had learnt different sorts of magical powers after leaving it.

Now most of the poorly people who came to see the Gatekeeper didn't need to see the Wizard. They were usually only slightly poorly or worried about being poorly and the Gatekeeper was very good at deciding who needed to see the Wizard. Most of the people seen by the Wizard were very poorly and the Wizard could cast his spells to make them better. The Wizard and the Gatekeeper needed each other.

\section{The Queen offers two solutions}

The problem was that as more people got older more and more of them needed to see the Wizard, and a queue began to form in the courtyard of the castle waiting to see him. Well, the people in the queue made such a noise that the Queen heard, and she summoned her Minister to explain what all the noise was about.

"The Wizard says he doesn't have enough money to treat all these poorly people," the Minister replied.

"There isn't enough money for all these new crystal balls and magic potions he keeps wanting," said the Queen. "He will just have to work faster and see more poorly people. He will have to send them home earlier before the magic potions have finished working and the Gatekeeper can look after them - it is about time that lazy Gatekeeper did more work and less golf."

Well the Wizard tried and the Gatekeeper tried but it was no good-in fact, the queue in the courtyard got longer and longer. Sometimes the Gatekeeper had to send back poorly people to the Wizard because they hadn't had enough of the magic potions before they came home. You have never heard such a noise that the people made-after all, they had given their money to 


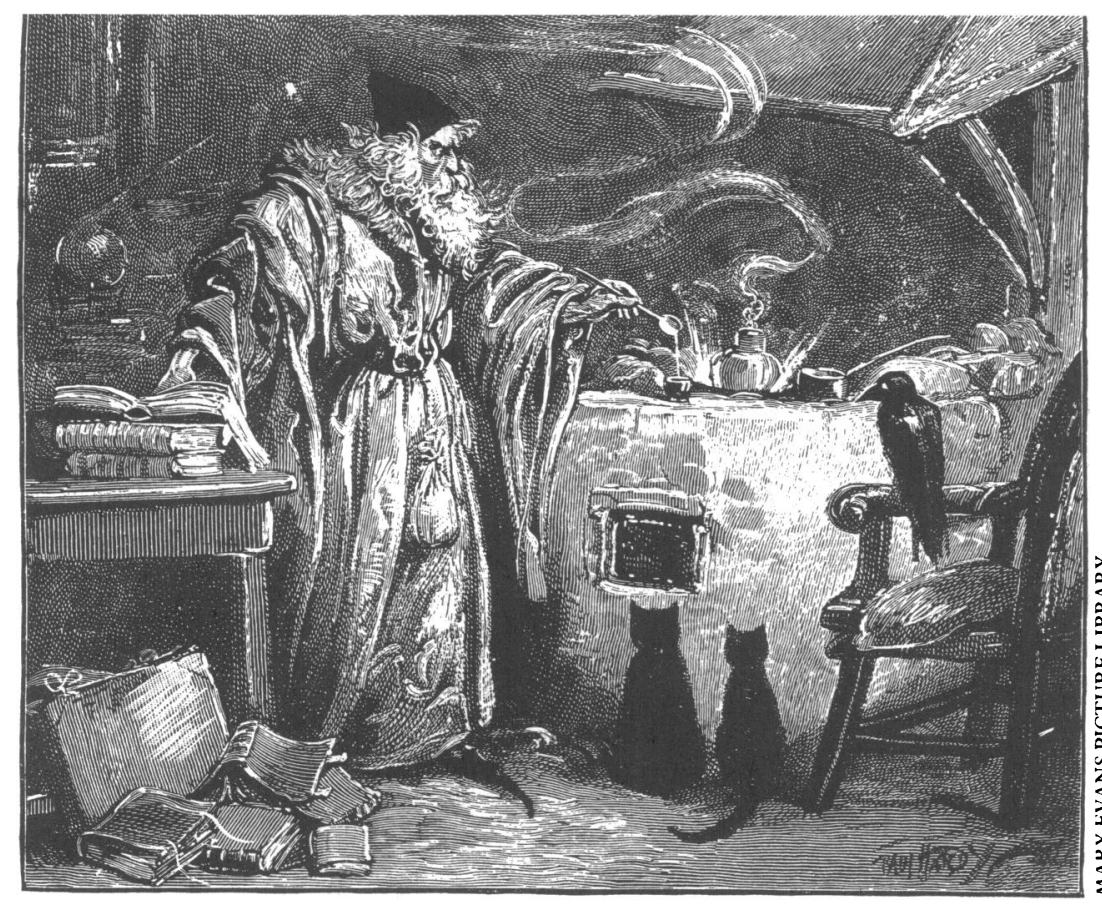

The Wizard asked the Minister for bigger and better crystal balls and more powerful magic potions. But it was no good
The Wizard, the Gatekeeper, and the Minister all looked at each other.

"It's because I could tell who was very poorly and needed to see the Wizard," said the Gatekeeper.

"Rubbish!" cried the Wizard. "It's because the Minister here won't pay for the best crystal balls and magic potions."

The Queen and the Minister looked at each other wearily. They had heard all this before and weren't impressed.

"Find out what is really going on," snapped the Queen. The Gatekeeper dialled DataSpell on his little crystal ball and in the twinkling of an eye there appeared the message:

The value of a diagnostic test depends on the prevalence of the condition in the population tested.

The Wizard and the Gatekeeper explain their magic

"Well what does that mean?" asked the Minister.

"It means that my crystal ball will work best on people who already have a high chance of having a disease," answered the Wizard. "If I use it on lots of people who aren't very poorly then it won't give the right answers."

The Minister looked completely lost. "Take this chap here," he said, grabbing a passing serf. "Supposing he comes to the Gatekeeper with a pain in his belly. How do you sort him out?"

"That's easy," answered the Gatekeeper. "I see about 150 of those in 18 months and examine them all. The 17 I think might be very poorly I send off to the Wizard pretty sharpish because they heed the most powerful magic spells straight away to make them better."

"But of those 17 I see," exclaimed the Wizard, "only seven are very poorly."

"Quite," said the Gatekeeper. "The chance of someone I see with pain in his belly being very poorly is only about $5 \%(7 / 150)$. The chance of someone you see being proper poorly is $41 \%$ (7/17)."

"And do you deal with the other $95 \%$ yourself then?" inquired the Minister, looking rather more impressed.

"Of course," replied the Gatekeeper. "Except for the odd one every few years who is very poorly but doesn't have any signs in his belly. That's the one that I keep my membership of the Wizard's and Gatekeeper's Protection Society up to date for."

"I see," said the Minister. "Although the Gatekeeper's false positive rate is about $59 \%(10 / 17)$, his false negative rate is zero, which means that all the very poorly people see the Wizard."

"And the chance of someone being very poorly among the people you see is much higher," he continued, turning to the Wizard.

"Or it was until you started messing about with the system," interrupted the Gatekeeper.

"What I don't understand," demanded the Queen imperiously, "is why don't the Wizard's crystal balls and magic potions work any more?"

"Ah that's the complicated bit," replied the Gatekeeper. "I am much better than the Wizard in deciding who is well and doesn't need to see the Wizard. That is to say I have a very high negative predictive value of $100 \%(133 / 133)$ but a low positive predictive value of $41 \%(7 / 17)$ for very poorly people. The Wizard, on the other hand, has a low negative predictive value but a high positive predictive value for very poorly people. He is very good at deciding who is very poorly but not nearly as good as I am at deciding who is well. Put another way I test for normality and he tests for illness - in fact, together we're unbeatable. If he starts doing my job and testing for normality with his crystal ball he gets into a frightful mess because it is calibrated for illness not normality." 
"So what you are saying is that we need you both," interjected the Minister quickly as the Gatekeeper drew breath. "If the Wizard's crystal ball and magic potions are going to work properly he should only see the people the Gatekeeper thinks have a high chance of being very poorly. And the Gatekeeper should see the people who think they might be poorly and try and find out if they are. Then at last the system can work efficiently and cheaply."

\section{And they all lived happily ever after?}

And so it came to pass. The ancient separation of Gatekeeper and Wizard was seen to be essential for the care of the people. Far from being a cosy arrangement depriving the people of choice and access to the Wizard it was the most efficient way of looking after the poorly people. Persuading the people of this, however, was much harder - a taste for direct access to crystal balls and magic potions once acquired is not easily forgotten. And as to whether the Queen gave the Wizard and the Gatekeeper enough money to run the system, well that's another story.

1 Department of Trade and Industry. Review of restrictive trade practices policy. London: HMSO, 1988.

2 Vecchio TJ. Predictive value of a single diagnostic test in unselected populations V Engl F.Med 1966;274:1171-3.

3 Edwards $M W$, Forman WM, Walton J. Audit of abdominal pain in general practice. I R Coll Gen Pract 1985;35:235-8.

\title{
How To Do It
}

\section{Lecture overseas}

\author{
David Lowe
}

People's reactions to an invitation to lecture abroad vary. There are those who know they could contribute but see nothing to gain, and those who dream of fame and fortune but don't consider the costs. Some lecturers think, like Nancy Mitford, that "Abroad is unutterably bloody": others seem to spend only a few weeks a year in the United Kingdom while they arrange their next trip. You will probably be flattered at the invitation, excited by the prospect of travel to foreign parts, faintly nervous at what you might be letting yourself in for, and game enough to suffer at least a little discomfort.

\section{Paperwork}

Once you have been invited to lecture abroad and have decided to accept the first hurdle is to get permission to go. For NHS staff this may simply be a matter of arranging cover with colleagues, but university employees may need the agreement of their dean and head of department as well. Permission to visit may be needed from the host country, and visas should be applied for early. Some consulates take months to process visa applications, and the fact that you simply must attend an international conference of important doctors will cut very little ice. On the application form you should state that you will be delivering a lecture or course of lectures, as this may determine the type of visa that you are given. For example, if there is a fee for the lecture you might not be allowed to accept it if a work visa has not been issued. Most travel insurance policies do not make separate provision for work abroad rather than tourism, but it is worth checking this. It is important to have medical insurance even if you are the guest of the ministry of health in the host country.

When you are invited somewhere you have never been many potential difficulties may be avoided if you can speak to someone who has been there. Your hosts may be able to give you names of previous lecturers. In any case try to agree with your hosts what the domestic and procedural arrangements are likely to be, and send them a list of your expectations well before you travel. For example, say that you understand you will be staying in a certain hotel, lecturing for so many hours, having this or that day free, and returning on a particular date. Try to get the address and telephone number of the hotel in which you will be staying so that you can be contacted if an emergency arises at home. Make sure that your hosts know the date and time of your arrival, and remember that days can be gained or lost if you cross the International Date Line.

For lecture courses some hosts arrange broad timings but courteously leave the details to the lecturer; if you are unaware of this you might find that the day of your arrival is spent drawing up a programme. Where possible the course contents and sequence of lectures should be agreed with your hosts and any other visiting lecturers before you go. Planning obviously relies on efficient communications. I once received a letter regretting that my trip had been cancelled four days after my planned departure date.

The way that you lecture will depend to some extent on the audience that you will be addressing. If it is not obvious ask yours hosts whether the audience will consist of medical students or postgraduates, generalists or specialists, and whether spouses, nonmedical staff, or the press will be invited. Terminology differs among countries. You can look up terms in a textbook in the host country's language. For example, the French and Russians are fond of eponyms, and the names might not be the ones that you are used to. We refer to the Circle of Willis but the French, with more geometrical precision, call it the Polygon.

\section{Audiovisual material}

The audiovisual and other material that you take will be determined by your style of lecturing and the information that you wish to convey and also by what facilities will be available at your venue. The equipment can vary from a blackboard without chalk to a three projector split screen son et lumière with a choice of independent or simultaneous advance and reverse. If you plan to use slides or overhead projection check that facilities will be available. If you are going to a humid climate remember that glass mounted slides may develop condensation which might boil from the heat of a powerful projector lamp and spoil the acetate.

Lecture notes or handouts prepared before you go will almost always be of better quality than ones photocopied immediately before a lecture, and they do not usually weigh much. When large numbers of notes are needed your hosts may be happy to help with postage or excess baggage charges on the flight, but check with them first. 